\title{
A tradução ética em “A Prova Do Estrangeiro"
}

Maria Emília Pereira Chanut ${ }^{1}$

RESUMO: O presente trabalho propõe uma reflexão que é uma tentativa de resgatar a matriz temática do estrangeiro como questão relacionada com a própria estrutura do texto literário. Essa relação parte essencialmente da noção de alteridade, ou seja, da relação com o outro - o estranho-estrangeiro da obra no original - e que está presente desde o momento de sua gênese. Um exemplo concreto do desafio que se apresenta ao tradutor será analisado a partir do próprio título da obra em questão: L’épreuve de l'étranger nos coloca num impasse - é a experiência, ou a prova? Do estrangeiro ou do estranho?

PAlAVRAS-CHAVE: Antoine Berman, tradução, literatura, estranho-estrangeiro, alteridade.

ABSTRACT: This paper attempts to rescue the theme of the foreigner and to relate it to the structure of the literary text. This relation derives, essentially, from the notion of otherness, that is, from the relationship with the other - the strange-foreign of the original work - which presents itself from the moment of its creation. A concrete example of the challenge the translator has to face will be given in our research, by the analysis of the title of the work: L'épreuve de l'étranger, which creates an impasse - does it refer to an experience or to a proof? To what is strange or to what is foreign?

KEYWORDS: Antoine Berman, translation, literature, strange-foreign, otherness.

\section{Introdução a Antoine Berman}

Antoine Berman, doutor em linguística e tradutor de literaturas alemã e latino- americana, faleceu em 1991, aos 49 anos. Ele é considerado na França um dos teóricos da tradução mais importantes na atualidade, país onde está sediada a Associação Antoine Berman, cuja equipe de membros fundadores foi formada por autores de renome como Jean-Christophe Bally, Yves Bonnefoy, Michel Deguy, Jacques Derrida, entre outros, o que confirma a notoriedade desse autor na esfera cultural e filosófica francesa contemporânea.

A obra de Berman desperta um interesse crescente e tem estado na origem da vitalidade da teoria da tradução, principalmente nas suas vertentes crítica e ética. Pode-se reconhecer a influência de sua teoria em trabalhos de outros teóricos da atualidade, tais como, Rosemary Arrojo (1996; 1997), no Brasil, Sherry Simon (1996) e Lawrence Venuti (1995), no exterior. Na vertente crítica, Berman nos deixou, em sua obra póstuma Pour une critique des traductions: John Donne (1995), um projeto em que renova o conceito de crítica de tradução, fundamentando-a na hermenêutica de Paul Ricoeur e Hans Robert Jauss.

Esse livro surgiu em vista de um seminário para o Collège International de Philosophie, como tentativa de síntese de seus diversos trabalhos sobre a tradução e, em particular, de seu livro L’épreuve de l'étranger (1984). Esse seminário, intitulado inicialmente “As análises de traduções", tinha como objeto de análise a escolha de um poema de John Donne,"Going to Bed”, confrontado a duas traduções francesas e uma mexicana, de Octavio Paz.

1 Professora doutora de Língua Francesa na Universidade Estadual Paulista - São José do Rio Preto (UNESP /IBILCE). Contato: chanut@ibilce.unesp.br. 
Assim, a primeira parte da obra trata da crítica de traduções, apresentada como um dos gêneros da Crítica, "com um C maiúsculo", diz ele, já que "crítica e tradução são estruturalmente parentes". No terceiro capítulo dessa primeira parte, Berman expõe seu próprio projeto crítico baseado na hermenêutica moderna, ou seja, pós-heideggeriana, e na crítica benjaminiana.

Num artigo anterior, de 1989, intitulado "La traduction et ses discours", Berman analisa os diferentes "discursos" sobre a tradução, mostrando suas insuficiências e introduz o seu próprio discurso, idealizando o que seria a "Tradutologia", que traz o elemento da reflexividade: segundo ele, tradutologia é a reflexão da tradução sobre si mesma a partir de sua natureza de experiência. Ou ainda, a tradutologia é a retomada reflexiva da experiência que é a tradução. Esse tema é retomado em sua obra principal, L'épreuve de l'étranger' (1984).

Essa obra é consagrada a um exame das teorias da tradução dos românticos alemães Novalis, Friedrich Schlegel até Schleiermacher, confrontando-as com outras reflexões que lhe são contemporâneas, de Herder, Goethe, Humboldt e Hölderlin.

Berman coloca nesse texto questões fundamentais, tais como: "O que é traduzir?", "Que lugar ocupa a tradução em uma cultura?”. Aborda também a relação do "próprio" e do "natal" com o estrangeiro, a essência da obra, a natureza da língua. Enfim, Berman busca definir quais são os passos obrigatórios para uma tradução hoje, que seriam: história da tradução, ética da tradução, analítica da tradução. Sem dúvida, nesse programa, ele dá primazia à ética, como "visada última da tradução", caracterizando sua "dimensão dialógica" essencial e redefinindo assim o significado de "fidelidade" na tradução.

\section{Tradução, literatura e cultura}

Em A prova do estrangeiro (2002), Antoine Berman coloca uma série de questões fundamentais, não só para a teoria da tradução, mas, igualmente, para sua relação mais genérica com a cultura literária, tais como a natureza da tradução e o lugar ocupado por ela em uma cultura. Além do problema específico da tradução, essa obra, importante também para os estudos de literatura, aborda questões mais amplas, que investigam os aspectos ontológicos da tradução implicados na relação do "próprio" e do "natal” com o "estrangeiro" e o problema da essência da obra e da natureza da língua.

A questão teórica mais específica da tradução literária relacionada ao tema do estrangeiro não poderia, a meu ver, ser dissociada de uma análise da tradição e da cultura dos que a realizam, sobretudo dos discursos que fazem sobre ela. Portanto, esta reflexão busca, primeiramente, evidenciar as questões socioculturais e literárias suscitadas pela obra de Berman, questões extremamente importantes para situar o panorama da tradução hoje, e intimamente ligadas com a crise de certa concepção contemporânea da literatura e da tradução ocidentais.

É importante enfatizar, em primeiro lugar, que Berman empreendeu a tarefa de escrever a história da cultura e da tradução na Alemanha romântica por duas razões: a

Neste artigo, as citações referentes a essa obra foram retiradas da tradução feita por mim, $A$ prova do estrangeiro. Cultura e tradução na Alemanha romântica (BERMAN, 2002).
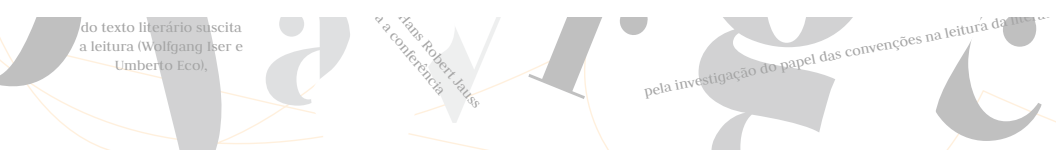
primeira, por ter encontrado nela toda a fascinação de um discurso poético e filosófico, inédito até então, sobre o ato de traduzir. A partir da idade clássica e romântica, o ato de traduzir passa a ser uma questão consciente e o autor esclarece que são as teorias elaboradas na Alemanha nessa época que, ainda hoje, determinam nossa concepção do traduzir. Todavia, como bem enfatizado pelo autor, são teorias especulativas, ou seja, que não consideram a prática do traduzir, nem a sua dimensão cultural e linguageira. É essa dimensão filosófica e especulativa, característica da reflexão romântica, presente também em sua literatura, que, segundo Berman, nos foi legada.

A segunda razão é que Berman diz ter encontrado no Romantismo alemão "a origem fascinante de nossa consciência literária [...] o duplo prestígio do teórico e do fantástico [...] a união do poético e do filosófico" (BERMAN, 2002, p. 41). Entretanto, foi curiosamente a partir da tradução das obras romanescas latinoamericanas, empreendida após essa experiência com o romantismo alemão, que Berman passou a reivindicar para a literatura e a tradução o resgate de uma dimensão histórica, cultural e linguageira, a buscar uma autoafirmação da tradução. Seu objetivo está inserido num contexto maior, o de uma viravolta da própria literatura, viravolta que visa a sair de certa tendência de desvio e afastamento em relação à magia dos mitos populares da tradição oral, da literatura trancada num universo de especulação filosófica, com preocupações formalistas e puristas.

Segundo Berman, foi a partir de Herder, no Classicismo alemão, que a obra passou a ser definida como uma singularidade referida às particularidades do próprio indivíduo, pois a unicidade da obra estava em seu tom, em sua expressão, abrindo caminho para um tipo de literatura que definiu os rumos do romance contemporâneo e transformou a literatura em um filosofar - sugiro aqui o modelo joyciano do monólogo interior ou do romance filosófico de Kafka como exemplos dessa trajetória do romance moderno cada vez mais distanciado de uma tradição romanesca de cultura popular. $\mathrm{O}$ que se pode constatar, principalmente a partir do século XX, é que a forma da reflexão na literatura ocidental, ao privilegiar o estilo e o autor, tomou um rumo intransitivo e passou a ser a própria obra, destituindo-a de sua dimensão dialógica e de suas raízes orais, de seu passado épico.

A crítica que Berman faz à tradição literária moderna enquanto herança dos românticos é, portanto, extremamente importante para a teoria da tradução, uma vez que a "teoria especulativa da tradução e a teoria intransitiva ou monológica da literatura estão ligadas" (BERMAN, 2002, p. 40-41). Em outras palavras, uma teoria da tradução moderna, na medida em que contesta as injunções culturais tradicionais, torna-se, segundo Berman, um "ato de descentralização criador consciente de si mesmo" e, enquanto "reflexão sobre si mesma”, promove "uma auto-afirmação da própria literatura" (BERMAN, 2002, p. 43-44).

Em relação ao que chama "modernidade literária", Berman cita Blanchot como um dos "exemplos surpreendentes, no século XX", da tendência atual dominante do monólogo e da intransitividade (BERMAN, 2002, p. 41). Por outro lado, Berman tem o cuidado de reconhecer que "nem tudo são monólogo e autor-reflexão na história da poesia e da literatura modernas" (BERMAN, 2002, p. 42), assim como nem tudo o é no Romantismo, apesar de considerar que o monologismo é uma tentação da poesia que a época moderna parece ter conhecido mais do que outras.
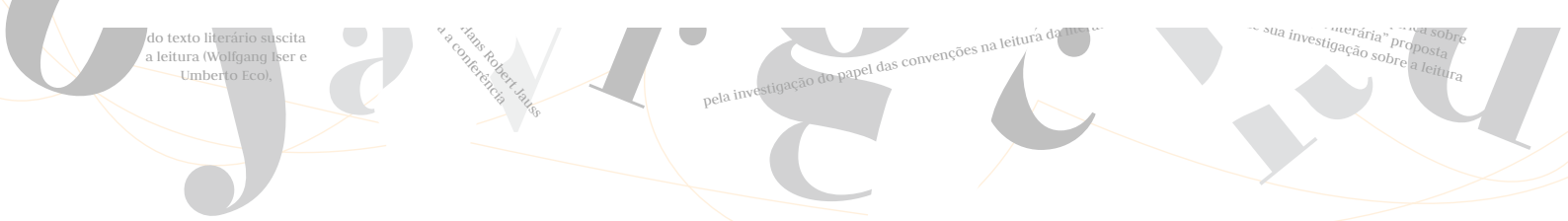
Mikhail Bakhtin, em sua Estética e teoria do romance, teria feito, segundo Berman, uma distinção inadequada e "brutal" entre o dialogismo do romance e o monologismo da poesia; contudo, apesar de admitir a existência desse tipo de radicalismo em sua tese, Berman acredita que, "afora todas as reformulações a se fazerem necessariamente na tese de Bakhtin, há, entretanto, nela, a indicação de uma dimensão, a dimensão dialógica, que pode modificar a nossa experiência da literatura e, correlativamente, da tradução" (BERMAN, 2002, p. 183-184). Ele considera o lírico, por exemplo, como um domínio fecundo, cuja extraordinária espessura textual o Romantismo não soube integrar. Assim, sua posição de repúdio a essa tendência de ordem intransitiva é explícita: é preciso, segundo ele, "recusá-la em nome da experiência de uma outra dimensão literária” (BERMAN, 2002, p. 42).

Diante desse panorama, pode-se dizer que, subjacente à questão da tradução, a reflexão em A prova do estrangeiro expressa as suas preocupações com uma "crise da alteridade", que se refere tanto à sociedade e à cultura francesas quanto à literatura ocidental como um todo. Ao que tudo indica, o drama causado pela relação com a alteridade (que é também o drama do tradutor) frequentemente reflete um medo de perda da identidade própria que pode estar presente tanto no nível do indivíduo, quanto no de um povo. Para adquirir a cultura que lhe faltava, a língua alemã teve que se abrir às línguas estrangeiras, mas, ao mesmo tempo, sem permitir um predomínio das mesmas devido ao medo da perda do natal, do próprio. A prova do estrangeiro define a tradução como a experiência que busca o equilíbrio entre a relação com o outro e a aprendizagem do próprio. Segundo o estudioso, com Lutero e sua tradução da Bíblia, a tradução surgiu pela primeira vez, na Alemanha, como "ato gerador de identidade" (BERMAN, 2002, p. 30), marcando o início de uma tradição que caracterizou a tradução como um processo de autoafirmação da língua nacional e, a partir de Herder, como um movimento oposto àquele que ocorria na França, onde, desde o século XVII, já imperava a tradução etnocêntrica.

Quanto à noção de alteridade no contexto do Romantismo alemão, "o princípio monológico age até na escolha dos textos a serem traduzidos: a tradução romântica só traduz obras românticas, só o mesmo. A experiência do estrangeiro como estrangeiro lhe é estrangeira" (BERMAN, 2002, p. 244). Berman aponta como possibilidade de diálogo entre as línguas e as culturas um caminho diferente, um gesto de abandono do mesmo, do conhecido, a ida de encontro ao outro, que resultaria em um espaço de mestiçagem no qual seriam valorizadas as especificidades e diferenças das culturas e das línguas de cada povo.

Trazendo essa questão para os dias de hoje, constatamos que A prova do estrangeiro, ainda que publicada em 1984, continua se inserindo em um cenário político e social francês atualíssimo, pois a questão do estrangeiro permanece na França como uma realidade muito preocupante. A alteridade e sua instância ética estão na pauta tanto dos pensamentos mais democráticos quanto nos de extrema direita, estes últimos marcados por uma postura etnocêntrica e, mesmo, xenófoba. A presença de estrangeiros significa, para alguns, um enriquecimento da cultura e, para outros, significa um perigo, uma ameaça. Essas preocupações, que remetem à figura "ameaçadora" do outro, do estrangeiro, do desconhecido, do imigrante, são questões políticas e sociais extensivas à reflexão literária e filosófica, pois marcam uma questão ética presente no pensamento humanista em geral. Assim, parece claro que também a atividade tradutória
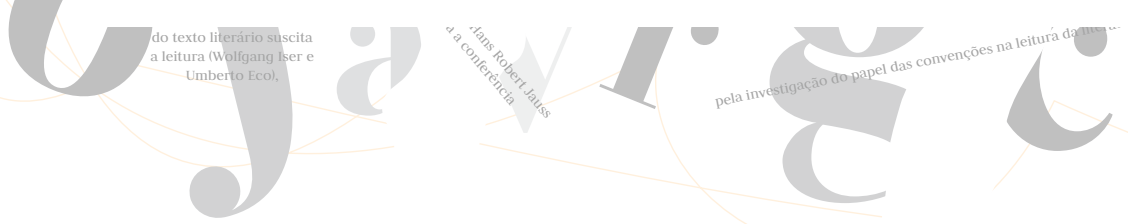
e, principalmente, o discurso que se faz sobre ela não são neutros ou inofensivos, pois a partir do momento em que falam de um respeito pela alteridade, fazem parte de uma redefinição de paradigmas políticos, sociais, éticos e literários.

No momento em que a reflexão sobre um texto dessa natureza é reconduzida no contexto brasileiro, somos inevitavelmente levados a refletir sobre a questão do outro também em nosso país e nossa cultura. Se a concepção do traduzir reflete a maneira pela qual uma sociedade se relaciona com o outro, seria fundamental que fossem propostos estudos que efetivamente descrevessem a história e a tradição da tradução no Brasil. A sociedade brasileira caminha num sentido duplamente inverso àquele da França, pois, diante da invasão estrangeira indiscriminada em nosso próprio território, o sentimento xenófobo parece não caber aqui, tampouco o nacionalista. A valorização hiperbólica da língua e da cultura estrangeiras constitui um desequilíbrio na relação com o outro que ameaça tanto nossa identidade quanto nossas diferenças, e essa é hoje uma realidade que, sem dúvida, pode ter sérias implicações para toda atividade cultural e artística. Até que ponto a nossa concepção do traduzir e também nossa literatura se mostrariam afetadas pela dominação do outro, por uma abertura desmedida ao estrangeiro? Que tipo de relação o tradutor brasileiro tem com a língua do estrangeiro?

Nesse sentido, cabe ainda lembrar aqui outro fenômeno da atualidade apontado por Berman que estaria profundamente ligado à dimensão monológica da linguagem e que ele qualifica como sendo o inverso de uma mestiçagem: ele se refere aos textos mal redigidos e submetidos ao domínio da língua dita universal, "parecendo más traduções de um mau inglês" (2002, p. 309, nota 55). Berman cita a cultura romana antiga e a francesa clássica que, como a norte-americana moderna, seriam exemplos de desejos inconscientes de dominação e apropriação do outro que, na tradução, opõem-se à sua visada ética essencial, que é de ser "abertura, diálogo, mestiçagem e descentralização" (BERMAN, 2002, p. 16). Ainda no que diz respeito ao inglês, Berman critica enfaticamente essa "homogeneização crescente dos sistemas de comunicação" (BERMAN, 2002, p. 324) que leva ao apagamento das diferenças, à destruição da capacidade de expressão oral das outras línguas, a um empobrecimento da criatividade literária na medida em que reduz a capacidade de simbolizar o mundo do modo que é peculiar a cada língua.

Enfatizando ainda a questão da tradução pelo viés da nacionalidade, lembrando do que foi mencionado anteriormente, a saber, como a tradição da tradução na Alemanha romântica definiu-se em oposição a uma cultura - a cultura clássica francesa, cujo modo de traduzir dominante é tradicionalmente caracterizado pelo etnocentrismo, um modo que privilegia a restituição embelezadora ou estetizante dos textos traduzidos, conhecidos no século XVII como Les Belles Infidèles. Berman refere-se, pois, a "tradições de tradução" diferentes porque, não só a ideia de tradução (ou sua problemática) se manifesta diferentemente em cada cultura, mas essas diferenças correspondem às diversas palavras pelas quais se nomeia a tradução.

Em seu artigo De la translation à la traduction (1988), Berman descreve a história da palavra tradução e mostra como significantes diferentes determinam visões culturais diferentes: assim, temos translation para o inglês, traducción para o espanhol, traduzione para o italiano e Übersetzen e Übertragung para o alemão. A raiz é a mesma

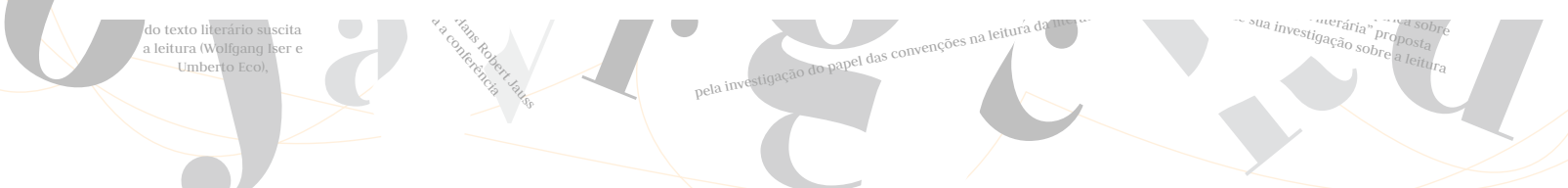


para as línguas latinas e nelas o conteúdo da ideia de tradução é mais aproximado, por outro lado, culturalmente e ideologicamente, translatio não equivale a traductio, pois a primeira, anglo-saxônica, pressupõe um movimento de transferência mais anônimo, mais amplo e concebe língua e linguagem como termos para a comunicação (o que, aliás, possibilitou sua universalização). Quanto à segunda, traductio, de origem latina, mas trazida do grego traductum, pressupõe um agente que "conduz", alguém agindo, promovendo transformações (os franceses transformam, adaptam, aclimatam ao seu bel-prazer). Muito interessante é o caso alemão, que tem duas palavras, constituindo igualmente manifestações diferenciais da ideia de tradução.

Em seu artigo La traduction et ses discours (1989), Berman retoma esse assunto, lembrando que, ainda que tenha consciência dessas concepções particulares a cada tradição e que a sua própria reflexão esteja enraizada na tradição francesa, o discurso sobre a tradução não é impedido de visar ao universal, nem de fazer dialogar as diferentes tradições.

Berman já havia apontado, em A prova do estrangeiro, os limites da tradição que definiu toda a tradução clássica no que se refere à relação com a alteridade. Humboldt, por exemplo, teve a pretensão de "exigir que a tradução nos faça sentir o estrangeiro, mas não a estranheza”. Para ele, isso significa "recusar a estranheza do estrangeiro tão profundamente quanto o etnocentrismo do classicismo francês". Ou seja, nessa região fronteiriça "obscura e perigosa" onde se situa a tradução, essa relação é marcada por um duplo perigo: o de uma estranheza desmedida ou de uma negação da dimensão do estrangeiro. Humboldt não teria tido êxito ao tentar traçar essa "linha divisória", ou ainda, não teria conseguido encontrar a dimensão do equilíbrio na relação com o outro (BERMAN, 2002, p. 278).

\section{Por uma tradução ética}

Berman acredita que é somente em uma "dimensão ética" que pode haver a busca desse equilíbrio por uma relação dialógica entre língua estrangeira e língua própria: “a tradução realmente ética deve evitar tanto o efeito de estranhamento abusivo quanto o efeito de naturalização abusivo" (BERMAN, 1995, p. 30). Essa dimensão parece constituir, portanto, o ponto de partida para uma reflexão moderna sobre a tradução, ancorada numa reflexão cuidadosa sobre a natureza da linguagem.

Em primeiro lugar, expor esse deslocamento que atenta para o outro parece tão necessário quanto expor o processo de produção do texto de partida e apontar para a atividade e o trabalho do escritor que leva as palavras ao seu limite, tornando-as estranhas até em sua própria língua. Esse processo da criação artística pode produzir uma resistência que impossibilita sua tradução e, assim, criar uma tensão que determinará a sua própria intraduzibilidade. Analisaremos, primeiramente, esse processo que ocorre no texto original, em sua gênese.

A palavra estrangeira, como toda palavra poética, pode sugerir uma significação oscilante que instaura uma tensão: a palavra é estranha e diferente e necessita ser traduzida, pois não a compreendemos, o que funda a necessidade da tradução; mas, ao mesmo tempo, o estrangeiro ou o estranho pode indicar o que é singular e único em uma língua ou em uma poesia, o que impossibilita a tradução, ou seja, resiste à
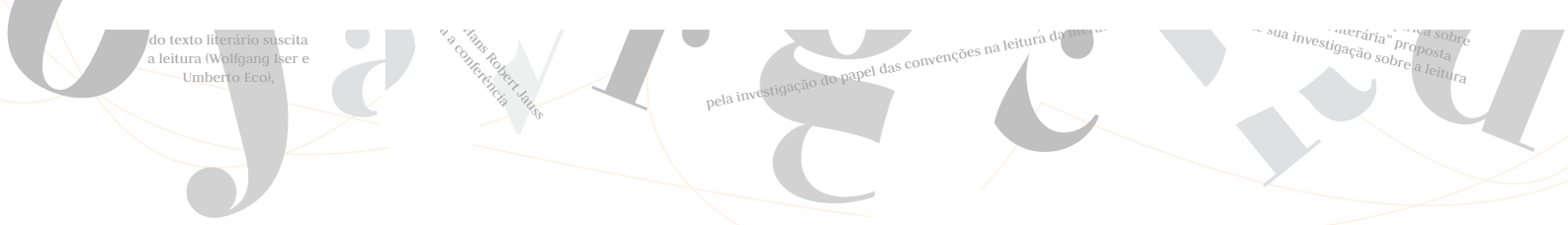
tradução, apontando para a sua intraduzibilidade. Sobre o intraduzível, Goethe comenta que a tradução trava uma "luta imediata com a língua estrangeira" (GOETHE apud BERMAN, 2002, p. 109). O momento decisivo da nomeação deixa as marcas dessa "luta", dessa escolha difícil. Berman acrescenta: "só o movimento da tradução faz aparecer a luta que se desenrolou no original" (BERMAN, 2002, p. 305).

Essas questões remetem às considerações que Berman faz sobre a tarefa do tradutor diante de um original que o solicita e resiste a ele, concomitantemente. No ato de tradução propriamente dito, de um poema ou de um romance, o tradutor detém-se diante de passagens que revelam, em sua estrutura original, "o movimento e a luta do pensamento que as produziram, caracterizadas por um alto grau de necessidade - são as chamadas zonas significantes" (BERMAN, 1995, p. 70-71). Essa "fase de gestação", como a nomeia este autor, não pode ser apreendida por uma "simples leitura" (BERMAN, 1995, p. 71). Ele acrescenta: "a obra final, mesmo estando acabada, definitiva, conserva sempre alguma coisa dessa fase de gestação, 'de tateamento' - todas as outras partes são marcadas por um caráter aleatório; assim, por não ter uma "necessidade escriturária absoluta, poderiam ter sido escritas de outro modo" (BERMAN, 1995, p. 71).

Essa necessidade de tradução pode estar presente, por exemplo, em um conceito filosófico que, ao surgir, é marca de uma forma intraduzível a princípio, mas que, desde seu surgimento, já solicita a sua tradução justamente por sua “diferença" e também por sua “novidade”. Cabe aqui lembrar o termo différance proposto por Derrida em 1968. É o que ocorre também no caso do surgimento de uma nova ciência, ou um novo pensamento, como, por exemplo, a psicanálise de Freud, cujo discurso surgiu de uma linguagem tirada do cotidiano e foi imbuída de novas significações. Sabe-se que o próprio Freud usava os termos ensaisticamente até que, em se tornando familiares, passassem a ser definitivos.

É justamente o caráter singular e irredutível do texto estrangeiro que nos remete, em seguida, a uma reflexão sobre a ética na tradução. Afinal, se, ao mesmo tempo, o tradutor é solicitado por um original e este lhe resiste, é somente através de um gesto de respeito ao outro - ao qual chamaremos, apoiados na obra de Jacques Derrida, de paradoxo da hospitalidade - que se pode praticar uma tradução responsável, ou seja, atender ao chamado do outro, considerando, ao mesmo tempo, o que há de irredutível nele.

Berman adverte que essa estranheza da língua do texto estrangeiro é "irredutível”, seja ele traduzido ou não, e que é um contrassenso considerar como má tradução aquela que "cheira à tradução". Sendo uma escritura que acolhe em sua língua própria a escritura de outra língua, a tradução não pode, "sob pena de impostura, fazer esquecer que ela é esta operação. Se toda escritura implica um horizonte de tradução, é absurdo pedir-se a uma tradução para aparecer como uma 'pura' escritura que é, ela mesma, um mito" (BERMAN, 2002, p. 278-280).

A partir da noção de alteridade, ou da relação com o outro, é preciso refletir sobre a ética na tradução em busca de uma redefinição do conceito de fidelidade. Nessa relação problemática, mas necessária com o outro, marcada pela constante tensão dessa dupla articulação - double bind -, parece fundamental uma reflexão sobre o paradoxo da hospitalidade, uma vez que essa relação problemática entre língua própria e língua estrangeira implica um certo modo de aceitação (hospitalidade) ou de rejeição (hostilidade).
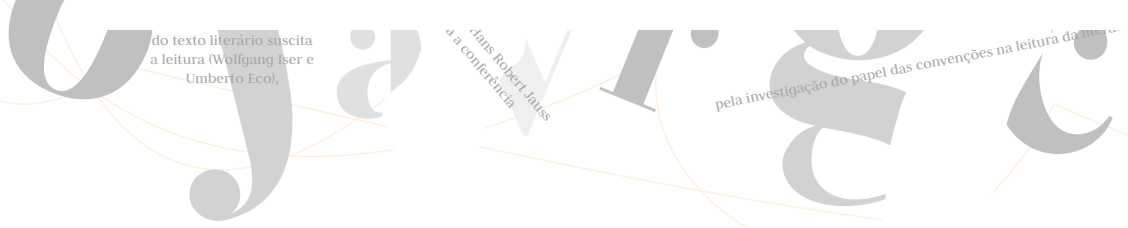
O problema da hospitalidade remete, primeiramente, ao problema da fidelidade na tradução: frequentemente confunde-se "respeito" com "submissão, atitude servil". Inversamente, corre-se o risco do que Berman chama de "a não-veracidade, a fraude" (BERMAN, 1995, p. 93). Manter uma fidelidade à "letra" não significa empregar uma "literalidade bruta" como disse Humboldt (BERMAN, 2002, p. 275), mas "respeitar a alteridade do texto", um "respeito pela letra da obra", um "certo respeito pelo original" (Berman, 1995, p. 92-93). Ele aponta para a consideração desses perigos e propõe uma relação aberta e explícita. Pensemos, por exemplo, na solução que recorre à não-tradução de um conceito original: ela pode ser válida, não por um desconhecimento do léxico, ou das possibilidades de paráfrases, mas sim na medida em que deixe claro que pretende explicitar a importância dessa decisão e que venha acompanhada por comentários e glosas. Além disso, é a não traduzibilidade de um termo estrangeiro que sempre possibilitou as trocas, os empréstimos, as contribuições de uma língua para outra ${ }^{3}$.

Em seus textos, Derrida lembra-nos que "abster-se" de fazer perguntas ou exigências ao outro, "oferecer o dom sem reserva" parece mais digno da hospitalidade absoluta e que essa abstenção, o "calar", já é uma modalidade da palavra possível (DERRIDA, 1997, p. 119). Também sugere, em “Des tours de Babel” que, “em razão dessa indistinção entre sentido e literalidade, o traduzível puro pode anunciar-se, dar-se, apresentar-se, deixar-se traduzir como intraduzível" (DERRIDA, 1987, p. 234). O que vai ao encontro de Berman (1984, p. 302), no que diz respeito à traduzibilidade: “É a própria estrutura do texto como texto que ditará aqui o que é preciso traduzir ou não traduzir [...] a não tradução de um termo valendo como um modo eminente de tradução" (DERRIDA, 1987, p. 339). Ou seja, não traduzir significa também um modo de traduzir. E acrescenta que o que a obra contém de estranho é seu elemento originariamente intraduzível e isso não deve ser encarado como uma limitação, pois a boa tradução mantém essa estranheza no novo texto e deve acolhê-la como tal, ou seja, é só em uma coexistência pacífica que podem habitar o próprio e o estrangeiro: "a boa tradução mantém essa estranheza tornando a obra acessível para nós" (BERMAN, 2002, p. 280).

Encontramos no texto De l'hospitalité (1987), de Derrida, uma reflexão importante sobre o estrangeiro. Ele demonstra como, paradoxalmente, existe no ser humano um desejo absoluto de uma hospitalidade incondicional que é imanente; ao mesmo tempo, existe um direito, uma política, uma ética que condicionam essa hospitalidade. Resumidamente, Derrida conclui que "tudo se passa como se a hospitalidade fosse impossível" (DERRIDA, 1987, p. 71), o que constitui, portanto, "uma antinomia insolúvel" (DERRIDA, 1987, p. 73), um conflito que marca a colisão de duas leis, opondo a Lei da hospitalidade ilimitada, incondicional, às leis da hospitalidade, que são esses deveres e direitos sempre condicionados e condicionais definidos desde a tradição greco-latina:

Entre uma lei incondicional ou o um desejo absoluto de hospitalidade de um lado e, de outro, um direito, uma política, uma ética condicionais, há distinção, heterogeneidade radical, mas também indissociabilidade. Uma solicita, implica ou prescreve a outra. (DERRIDA, 1987, p. 131)

Vale lembrar o reverso da medalha: trata-se da tradução que, para "respeitar" a beleza do outro, tem que transformar (cf. Derrida, 1998).
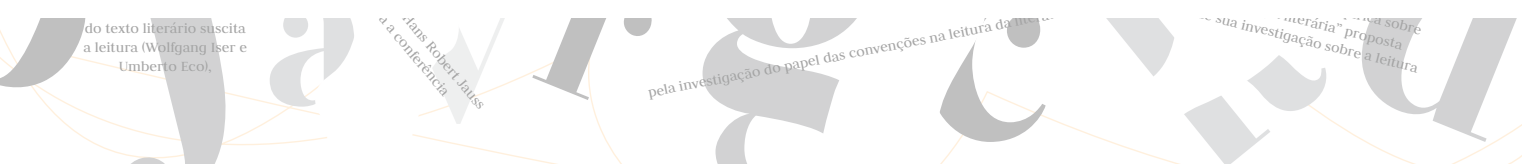
Esse paradoxo está presente na tradução como "lei necessária e lei impossível”, como explica Marcos Siscar em Jacques Derrida, o intraduzível (2000), afirmando que "é essa responsabilidade da tradução diante da hospitalidade ou da violência de seu gesto que deveria, portanto, ser alçada à condição de questão para o tradutor" (SISCAR, 2000, p. 69). Derrida lembra que a questão da tradução está o tempo todo implicada nessa experiência da hospitalidade. "O convite, a acolhida, o asilo, passam sempre pela língua ou pela comunicação com o outro" (DERRIDA, 1987, p. 119). Ele cita Lévinas: “A linguagem é hospitalidade”.

\section{Etrange-étranger}

Estaria, portanto, na origem da palavra "hôte" a origem do paradoxo. Em francês, "hôte" significa, ao mesmo tempo, o anfitrião e o hóspede. Buscando a origem latina desta palavra, Derrida descobriu que "hostis" significa ao mesmo tempo hóspede ou inimigo (hospitaleiro ou hostil). Em seguida, apoiado nas interpretações de Benveniste das duas derivações latinas, ele elabora uma brilhante síntese lexical: "hospitalidade, hostilidade, hostipitalidade”. Significantes e significados se relacionam, exibindo e conservando sua alteridade, ao mesmo tempo oposição e união. A tradução de Derrida caracteriza uma experiência única de leitura, pois responde ao desafio lançado pelo outro e traduz simultaneamente os dois movimentos possíveis: sua tradução é um ato poético.

Sugiro uma análise semelhante a propósito da palavra étranger, indo às suas origens etimológicas. Estaremos passando, assim, por certa “prova do estrangeiro", praticando uma experiência da tradução de acordo com os ensinamentos da tradução luterana da Bíblia e das poesias e traduções de Hölderlin.

Constata-se, a princípio, que étranger é irrecuperável "como termo isolado" na tradução para o português, caracterizando uma "experiência do impossível” partindo da impraticável experiência de uma recuperação total de sentidos, de uma "perfeita equivalência" ${ }^{14}$. Portanto, "épreuve de l'étranger" é um convite à reflexão sobre a necessidade da consideração da alteridade, do respeito pelo caráter irredutível e intraduzível de um texto. Apesar do drama do tradutor diante desses "dilemas", o que deve permanecer presente nessa escolha é o seu gesto hospitaleiro, o seu questionamento. No momento dessa escolha, ele deve assumir a responsabilidade por sua decisão. O que deve permanecer visível nesse ato é a busca de uma ética.

A tradução que cultiva essa dimensão ética procura possíveis semelhanças linguísticas e culturais, mas preserva as diferenças, mantém a estranheza, a fim de manter viva nesse processo a percepção de suas aporias fundamentais, a percepção daquilo que, em toda tradução, permanece misterioso e indomável. A constante busca do equilíbrio em meio à diversidade só seria possível a partir de uma consciência da transformação e, por essa razão, a linguagem do "novo original” é frequentemente híbrida, ao mesmo tempo impura e enriquecedora. Uma tradução "responsável” pode ser considerada

Sobre a noção de equivalência, conferir o livro de Cristina Carneiro Rodrigues (2000). Conferir também a noção de “correspondência” proposta por Berman (1995, p. 94) como possibilidade para se conceituar a relação do texto traduzido com o original e sua língua. 
"ética" na medida em que é hospitaleira, ou seja, acolhe o outro por meio do diálogo, da exposição da estranheza, da relação com o outro.

Por outro lado, uma tradução não ética, ou etnocêntrica, pratica um narcisismo cultural no momento em que, buscando um reconhecimento próprio ao trazer o texto para o nosso horizonte de perspectivas, encontra tão somente "o mesmo" no "outro", romanticamente. Negando a "estranheza" do outro, suas diferenças, além de impedir que a relação e o diálogo se estabeleçam, se oculta também a sua beleza e, portanto, a sua riqueza. Berman nos mostrou o que fez o gênio de Hölderlin ao traduzir Sófocles, ao evocar, revelar o outro que já existia no grego, ao dialogar com o grego, articulando-o ao elemento dialetal do alemão e instaurando um equilíbrio nessa dimensão do "Diferenciado" (BERMAN, 2002, p. 298), na qual a experiência do estrangeiro e a experiência do próprio estão finalmente em coexistência.

Afinal, passar pela prova do estrangeiro é como passar por uma experiência de viagem, em que sempre permanece o difícil momento da escolha. Como se pode dizer também a propósito do discurso literário, essa experiência de viagem tem dois tipos de manifestação: pode ser reduzida à "grande viagem" romântica, cuja passagem pelo outro não o percebe em sua diferença, pois só busca a si mesma, ou pode ser "a única verdadeira viagem" de que falava Proust em A Prisioneira: "não é a de ir ao encontro de novas paisagens, mas a de ter outros olhos". Em outras palavras, nem sempre o outro é o novo, mas é o fato de "olhar" atentamente para o outro que possibilita novas descobertas.

Em A prova do estrangeiro, o título já aponta mais de um desafio ao tradutor: a palavra épreuve sugere várias possibilidades, como colocar à prova, sofrimento, prova de coragem, de resistência... O outro desafio vem com a palavra étranger que, na língua francesa, oscila permanentemente entre dois significados que sempre andam juntos, são indissociáveis, formando um só e dois ao mesmo tempo: o estranho-estrangeiro.

Vejamos resumidamente, as acepções de étranger descritas no dicionário Le Petit Robert: (séc. XIV; de estrang(i)er) como adjetivo, pode significar: xenófobo; exterior; diferente, distinto, isolado; desconhecido; estranho; ignorante, profano; insensível; como substantivo, pode significar: imigrante; refugiado; cosmopolita; desconhecido; terceiro. Curiosamente, se conferirmos o verbete étrange, temos: (Estrange “étranger", v.1100; lat. extraneus "étranger”). Como adjetivo pode significar: bizarro, curioso, esquisito, extraordinário, singular; indefinível; surpreendente, incompreensível, inexplicável, original; desacostumado, inquietante, insólito; excepcional, raro; anormal; como substantivo: estranheza.

Fica bastante claro, em um primeiro momento, que as duas palavras se misturam, tanto nos sentidos, quanto em suas etimologias. Tanta riqueza de sentidos, tantas possibilidades para uma só palavra, colocam-nos em situação crítica, pois, como diz Berman, a tradução busca "corresponder" na pluralidade de todas essas significações (BERMAN, 1995, p. 94). Não seria precisamente o que se passa no início, no momento em que o escritor negocia com o léxico, quando todas as possibilidades da palavra instauram um diálogo no interior da própria linguagem? Esse "drama do nome”, como diz Derrida $^{5}$, caracteriza um momento único, um evento singular, que é a criação poética

Expressão usada por Derrida em “Prejugés, devant la loi” (1985). 
e é precisamente o que ocorre no ato de traduzir uma obra. Diante disso, pode-se dizer que a tradução é a renegociação desse evento em outra língua.

Diante dessa dimensão real e inegável da restituição dos sentidos em que a experiência da tradução se realiza, surge uma dimensão maior, aquela que Berman chama de "trabalho sobre a letra" (1989, p. 676). Não se trata da simples interpretação de um texto, de uma reconstrução subjetiva dos sentidos. Compreendemos a letra literária como sendo a significância que representa o momento em que ele foi tecido, sua história, suas circunstâncias e que constituem a letra, o corpo verbal do texto. O trabalho sobre a letra que o tradutor faz remete a essa experiência que é a própria tradução e, para Berman, só ela pode proteger o texto de "qualquer arbitrariedade subjetiva", definindo a tradução como "uma relação mais responsável do que outras” (1989, p. 271-272). Entenda-se aqui subjetivo como individual, não como oposto a objetivo.

A propósito dessa diferenciação entre a simples leitura de um texto, sua interpretação e o ato de traduzir, vale citar o que diz Luiz Costa Lima na orelha do livro de Wolfgang Iser, a propósito da interpretação de um texto:

\footnotetext{
a carência de sentido que a obra literária traz consigo se atualiza em um paradoxo: a atualização do efeito nem está previamente dada, nem é arbitrária. Por isso, a interpretação, a doação de sentido, tanto varia historicamente, como mantém, em cada momento histórico, uma certa semelhança interna. (LIMA, 1999)
}

Em outras palavras, na leitura e interpretação de um texto há "simultaneamente" a recepção de um sentido da obra e uma recomposição da mesma, efetuada pelo sujeito mediante um "estranhamento" que o leva a tentar compreender aquilo que o supera. Assim sendo, segundo as teorias da estética da recepção, a leitura de um texto apresenta "vazios" que vão sendo preenchidos com "possibilidades" nunca definitivas. O "possível" que habita essa escrita engendra uma resposta participativa e atualizada, ou seja, uma resposta do aqui e agora. Não desconsideramos, portanto, essa dimensão cultural que determina a maneira como percebemos um texto em um determinado lugar e uma determinada época e também como outras culturas de outras épocas e de outros lugares perceberam esse mesmo texto. Borges nos presenteia com uma magnífica reflexão a esse respeito no seu Pierre Ménard ${ }^{6}$.

A tradução seria mais responsável porque antes de interpretar e compreender vai ao fundo do se fazer da obra. Essa pré-leitura que pratica o ato de traduzir pode ser considerada um "ato poético" a partir do momento em que penetra naquele estado paradoxal original e expõe sua duplicidade, sua dialética, nunca a "resolvendo".

Para Lévinas, "a idéia de um amor que seria a (com) fusão entre dois seres é uma falsa idéia romântica [...] a relação não neutraliza ipso facto a alteridade, mas a conserva" (1982, p. 59). A tradução literária moderna, em seu estágio de autonomia e legitimidade seria a experiência que exibe a tensão verbal original da obra, situando-a numa dimensão dialógica, onde acolher o "outro" supõe "relação" com o outro e não "apropriação".

${ }^{6}$ Vale conferir o que diz Arrojo sobre o tradutor e esse "personagem" borgiano (1992, p. 15).

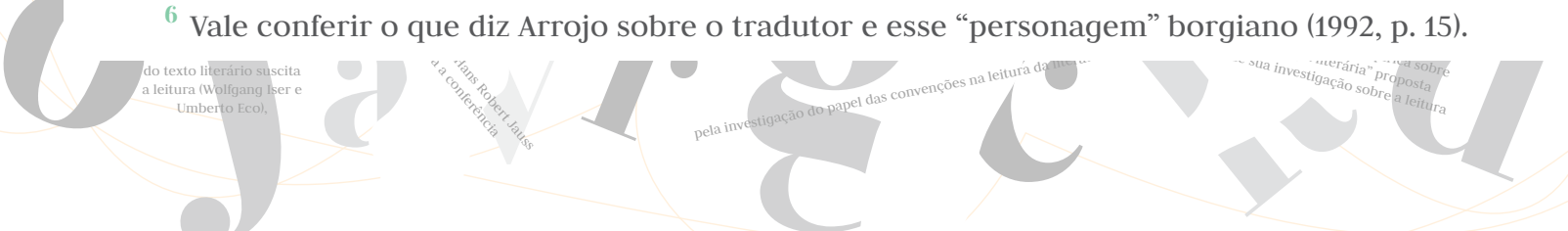


É extremamente importante atentar para a definição do original descrita por Berman como sendo não um dado inerte, mas "o lugar de uma luta" (BERMAN, 2002, p. 303). Essa luta seria o combate que trava a língua, quando, na dimensão dialógica da linguagem poética, busca um equilíbrio entre o que é diferente e o que é familiar. O original enquanto "luta" é importante para que se perceba um movimento constante de busca do outro dentro da própria língua e, portanto, desmascara a concepção de estabilidade, de univocidade do texto original.

\section{Tradução: estranha experiência}

O desafio maior que étranger encerra em si é toda a problemática da tradução e não somente o de sua tradução. O fundamental, nesse desafio, é estarmos atentos à alteridade e termos consciência de que as possibilidades não são definitivas, nem únicas.

Ao entrarmos em contato com o texto estrangeiro, é com a língua do outro que nos defrontamos, seu contexto cultural e ideológico, seu diálogo com outros textos, seu momento histórico e social, enfim, todas as marcas individuais e coletivas vêm impressas na sua língua. O próprio trabalho de produção textual do escritor já contém um processo de enfrentamento do outro à procura de sua própria identidade.

Conscientes desse estrangeiro irredutivelmente estranho e diferente, desse estranho-estrangeiro - étrange-étranger - não há como escapar da escolha: acolhê-lo ou rejeitá-lo. A tomada de consciência de sua irredutibilidade não basta para evitar o conflito desta escolha, mas permite descobrir que nós também temos nossas diferenças, singulares e únicas, o que pode contribuir para começar a olhar para o outro de outra forma.

Como acolhê-lo, porém, é o nosso drama enquanto tradutores. Recusar o que é diferente implica recusar-se a conhecê-lo, bani-lo para sempre de nossas vidas, evitar qualquer contato, qualquer relação, preferindo permanecer no mesmo, inalterados. Sem o enfrentamento do perigo da relação, não há diálogo, nem troca, não há possibilidade de tradução, há somente uma espécie de monólogo. A prova do estrangeiro é, antes de tudo, o resultado de um longo diálogo com Antoine Berman e essa experiência terá irremediavelmente metamorfoseado, de algum modo, ele próprio e nós todos.

\section{Referências Bibliográficas}

ARROJO, R. O signo desconstruído. Campinas: Pontes, 1992.

BAKHTIN, M. Questões de Literatura e de estética. São Paulo: Unesp/Hucitec, 1998. BERMAN, A. L'épreuve de l'étranger - Culture et traduction dans l'Allemagne romantique. Paris: Gallimard, 1984.

. De la translation à la traduction. In: Traduction et culture(s). Université du Québec

à Trois-Rivières, 1er semestre 1988. TTR: traduction, terminologie, rédaction, volume

1, n. 1, p. 23-40.

La traduction et ses discours, Meta XXXIV, 4, Paris, 1989.

. Traduction spécialisée et traduction littéraire. Actes du Colloque International.

Paris, 21 et 22/03/1991. 
. Pour une critique des traductions: John Donne. Paris: Gallimard, 1995.

A prova do estrangeiro. Cultura e tradução na Alemanha romântica: Herder, Goethe, Schlegel, Novalis, Humboldt, Schleiermacher, Hölderlin. Trad. Maria Emília Pereira Chanut. Bauru: EDUSC, 2002.

DERRIDA, J. “Préjugés, devant la loi”. In: La faculté de juger. Paris: Minuit, 1985.

“Des tours de Babel”. In: Psyché - inventions de l'autre. Paris: Galillé, 1987.

De l'hospitalité. Paris: Calmann-Lévy, 1997.

. “Carta a um amigo japonês”. Trad. Érica Lima. In: OTTONI, P. (org.). Tradução - a prática da diferença. Campinas: FAPESP/UNICAMP, 1998.

ISER, W. O ato da leitura. Vol. 2. Trad. Johannes Kretschmer. São Paulo: 34, 1999.

LÉVINAS, E. Éthique et infini. Paris: Fayard, 1982.

RODRIGUES, C. C. Tradução e diferença. São Paulo: Editora UNESP, 2000.

SISCAR, M. A. Jacques Derrida: o intraduzível. Alfa (São Paulo), v. 44, 2000, p. 59-69.

ArTigo ReCEBIDO EV: 31 jul. 2012

ARTIGO ACEITO EM: 12 set. 2012

Referência eletrônica: CHANUT, Maria Emília Pereira. A tradução ética em A prova do Estrangeiro. Revista Criação \& Crítica, n. 9, p. 161-173, nov. 2012. Disponível em: <http://www.revistas.usp.br/criacaoecritica>. Acesso em dd mmm aaaa. 